\title{
Evaluation of Treatment Changes in the Maxillary Intercanine and Intermolar Width in Patients with Various Malocclusions: A Study Model Analysis
}

\author{
Isha Aggarwal ${ }^{1} \quad$ Adarsh Deep Kharel $^{1} \quad$ Sanjay Mittal ${ }^{1}$ \\ ${ }^{1}$ Department of Orthodontics and Dentofacial Orthopedics, Bhojia \\ Dental College and Hospital, Baddi, Himachal Pradesh, India
}

\author{
Mandeep K. Bhullar ${ }^{1}$ Tanzin Palkit
}

\author{
Address for correspondence Adarsh Deep Kharel, MDS, \\ Department of Orthodontics and Dentofacial Orthopedics, \\ Bhojia Dental College and Hospital, Baddi 173205, \\ Himachal Pradesh, India (e-mail: addy_lampard @yahoo.com).
}

\begin{abstract}
Keywords

- intercanine width

- intermolar width

- study model analysis

Introduction Since extraction and nonextraction is a debatable topic to date, its effects on the changes in the dimension of arch width are unclear. Many investigators suggested that extraction would lead to arch collapse, whereas few others suggested that such changes in dimension would not occur.

Aim and Objectives To evaluate the changes in the intercanine and intermolar width in premolar extraction cases in class I and class II div 1 malocclusion cases.

Materials and Methods The study included pretreatment and posttreatment study models of 25 patients ( 14 with class I malocclusion, 11 with class II division 1 malocclusion). Intercanine and intermolar widths were measured and evaluated for both the malocclusions. The difference posttreatment intercanine width and intermolar width between class I and class II division 1 malocclusion were also assessed. The values obtained were subjected to statistical analysis.

Results There was no statistically significant difference in the intercanine and intermolar width pre- and posttreatment for class I patients, but there was a statistically significant difference in the intercanine and intermolar widths in class II patients. When class I and class II patients were compared for the parameters (intercanine/intermolar widths), it showed that there was no statistically significant difference.
\end{abstract}

\section{Introduction}

An individual treatment is planned for each patient in accordance with current orthodontic procedures, with therapy methods selected to fit the particular needs of the patient. Constricted maxillary arch demands rapid maxillary expansion, whereas excessively protrusive profile demands permanent teeth extraction. In cases where signs are misjudged, therapies involving extractions will affect not just the expression of the smile but also the whole face, leading to patients with "dish-in" profiles.

Changes within arch dimensions after extraction of teeth are still a debatable topic. There are various schools of

\section{published online}

December 12, 2020
DOI https://doi.org/

$10.1055 / \mathrm{s}-0040-1721878$ ISSN 2321-1482. thought regarding the same. Many reports have shown that orthodontic extraction can lead to arch collapse, resulting in a smaller diameter of the arch. Other studies, however, have shown that the technique of extraction therapy to overcome malocclusion would not lead to arch narrowing compared with associated categories of nonextraction.

Typically, extraction does not result in a smaller arch diameter compared with nonextraction therapy. Some authors reported a widening of the intercanine maxillary width in patients with extraction, but Germec-Cakan ${ }^{1}$ found no substantial changes. An expansion in the intercanine mandibular width was registered in patients with the extraction. The intermolar diameter, on the other hand, continues to decrease

C2020. Bhojia Dental College and Hospital affiliated to Himachal Pradesh University.

This is an open access article published by Thieme under the terms of the Creative Commons Attribution-NonDerivative-NonCommercial-License, permitting copying and reproduction so long as the original work is given appropriate credit. Contents may not be used for commercial purposes, or adapted, remixed, transformed or built upon. (https://creativecommons.org/licenses/by-nc-nd/4.0/).

Thieme Medical and Scientific Publishers Pvt. Ltd. A-12, 2nd Floor, Sector 2, Noida-201301 UP, India 
during extraction therapy in both jaws. Some researchers believe that the width of the arch is a significant factor in creating an "absolute smile"2 and that extraction treatments limit arch form, ${ }^{3}$ whereas others suggest that smile aesthetics are not based on arch width alone ${ }^{4}$ and that extraction treatments do not limit arch shape. ${ }^{5}$

The only well-accepted fact about extraction is that it will change the arch width and, these modifications will occur until the completion of therapy.

\section{Aim and Objectives}

This study aimed to evaluate treatment changes of maxillary intercanine and intermolar widths in patients who have undergone first premolar extractions.

\section{Materials and Methods}

The study was conducted on pre- and posttreatment models of 25 patients aged 14 to 25 years (13 males and 12 females), who were registered with the Department of Orthodontics and Dentofacial Orthopedics, Bhojia Dental College and Hospital, Baddi, India, for fixed orthodontic care. Based on the Angles classification scheme, patients were grouped into the following two categories:

- Group A: class I ( $N=14,9$ males and 5 females).

- Group B: class II division 1( $N=11 ; 7$ females and 4 males).

\section{Inclusion Criteria}

The inclusion criteria included the following:

- No dental abnormality

- No teeth congenitally absent

- No teeth were removed prior to preparation for orthodontic treatment.

- Upper 1st premolar extraction during treatment

\section{Exclusion Criteria}

The inclusion criteria included the following:

- Absence of any restoration covering the cusp of the teeth to be measured.

- Absence of any pathological condition.

- No gross abnormality.

- No severe crowding (-Fig. 1).

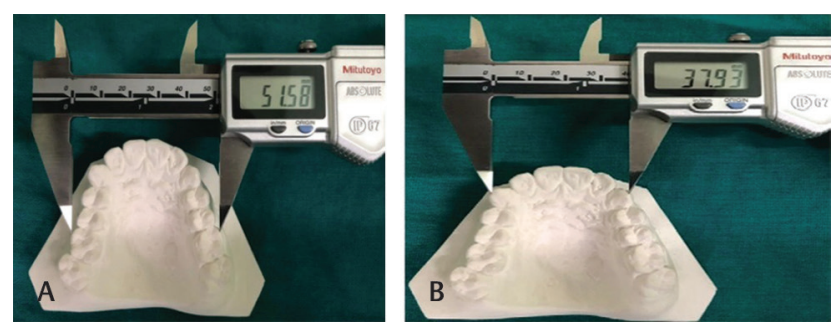

Fig. 1 Parameters measured on the study models were: (A) Intermolar width: distance from the mesiobuccal cusp tip of one upper first molar to the contralateral molar mesiobuccal cusp tip. (B) Intercanine width: distance from the maxillary canine cuspal tip to the contralateral canine cuspal tip.

\section{Statistical Analysis}

The observed value was subjected to statistical analysis, which was performed using SPSS (IBM Corp., Armonk, New York, United States). For the reported parameters in both classes, the mean, standard deviation, and maximum and minimum values were obtained. Comparison between preand postparameters in class I and class II was made using paired $t$-test. Comparison of parameters between class I and class II malocclusions was made using the independent sample test for equality of means.

\section{Results}

The study was conducted on pre- and posttreatment study model of 25 patients aged between 14 and 25 years (13 males and 12 females), who reported to the Department of Orthodontics and Dentofacial Orthopedics, Bhojia Dental College and Hospital, for fixed orthodontic treatment. Patients were divided into two groups on the basis of Angles system of classification as group A, class I $(N=14 ; 9$ males and 5 females), and group $\mathrm{B}$, class II division $1(N=11$; 7 females and 4 males). All the patients in the upper arch were exposed to the first premolar removal management regimen. The parameters measured on study models were intercanine width and intermolar width. In addition to standard descriptive statistical calculations (mean and standard deviation) for pre- and postparameters, a descriptive statistical calculation of pre- and postparameters of the overall sample was also performed. A paired $t$-test was employed to assess pre- and posttreatment values in class I and class II samples. The results were evaluated within a 95\% confidence interval. The statistical significance level was established at $p<0.05$. An independent $t$-test was employed to compare the parameters between class I and class II division 1 (-Table 1 ).

The descriptive statistics for the treatment parameters studied for group A (class I) and group B (class II division 1) are given in - Table $\mathbf{2}$. The mean values for the intercanine width posttreatment $(37.32 \mathrm{~mm})$ and the intermolar width posttreatment ( $50.75 \mathrm{~mm}$ ) were increased in class I patients. Class II division 1 cases too showed the same result, where there was an increase in the mean values of intercanine width posttreatment $(36.73 \mathrm{~mm})$, whereas there was a decrease in the mean value of the intermolar width posttreatment $(48.45 \mathrm{~mm})$ in class II patients.

The descriptive statistics for the treatment parameters studied for the overall sample are given in -Tables $\mathbf{2}$ and $\mathbf{3}$. There was an increase in the mean values of intercanine width posttreatment (37.06) and a decrease in the mean values of intermolar width posttreatment (49.74) in the overall sample.

A paired $t$-test was applied for comparison between preand posttreatment parameters (intercanine and intermolar) in class II to analyze their mean values ( $\mathbf{- T a b l e s} \mathbf{4}$ and $\mathbf{5}$ ). The mean differences were found to be statistically significant for intercanine width $(p=0.001)$ as well as for the intermolar width $(p=0.012)$.

Since the parameters were not normally distributed, Mann-Whitney and Wilcoxon tests were used to know 
Table 1 Descriptive statistics of pre- and posttreatment parameters in class I and class II

\begin{tabular}{|l|l|l|l|l|l|l|l|l|}
\hline \multirow{2}{*}{ Parameter } & \multicolumn{3}{|l|}{ Group A (class I, N=14) } & \multicolumn{2}{l|}{ Group B (class II, N= 11) } \\
\cline { 2 - 9 } & Mean & SD & Max & Min & Mean & SD & Max & Min \\
\hline $\begin{array}{l}\text { Intercanine width } \\
\text { (pretreatment) }\end{array}$ & 36.15 & 4.24 & 42.00 & 25.00 & 34.14 & 2.24 & 39.00 & 30.00 \\
\hline $\begin{array}{l}\text { Intermolar width } \\
\text { (pretreatment) }\end{array}$ & 51.64 & 4.26 & 62.00 & 45.00 & 49.64 & 1.73 & 53.00 & 46.00 \\
\hline $\begin{array}{l}\text { Intercanine width } \\
\text { (posttreatment) }\end{array}$ & 37.32 & 1.99 & 41.00 & 33.00 & 36.73 & 2.16 & 40.00 & 34.00 \\
\hline $\begin{array}{l}\text { Intermolar width } \\
\text { (posttreatment) }\end{array}$ & 50.75 & 2.29 & 57.00 & 48.00 & 48.45 & 1.52 & 51.00 & 46.00 \\
\hline
\end{tabular}

Abbreviation: SD, standard deviation.

Table 2 Descriptive statistics of pre- and posttreatment parameters in the overall sample

\begin{tabular}{|l|l|l|l|l|l|}
\hline Parameter & N & Mean & SD & Max & Min \\
\hline $\begin{array}{l}\text { Intercanine width } \\
\text { (pretreatment) }\end{array}$ & 25 & 35.26 & 3.59 & 42.00 & 25.00 \\
\hline $\begin{array}{l}\text { Intermolar width } \\
\text { (pretreatment) }\end{array}$ & 25 & 50.76 & 3.48 & 62.00 & 45.00 \\
\hline $\begin{array}{l}\text { Intercanine width } \\
\text { (posttreatment) }\end{array}$ & 25 & 37.06 & 2.04 & 41.00 & 33.00 \\
\hline $\begin{array}{l}\text { Intermolar width } \\
\text { (posttreatment) }\end{array}$ & 25 & 49.74 & 2.27 & 57.00 & 46.00 \\
\hline
\end{tabular}

Abbreviation: SD, standard deviation.

Table 3 Comparison between class I pre- and posttreatment parameters

\begin{tabular}{|l|l|l|l|l|l|l|}
\hline \multirow{2}{*}{ Parameters } & \multicolumn{2}{l|}{ Class I (pre- and posttreatment) } & \multicolumn{2}{l|}{ Difference } \\
\cline { 2 - 8 } & Mean & SD & SE & $t$ & $\begin{array}{l}\text { Sf } \\
\text { (two-tailed) }\end{array}$ \\
\hline Intercanine width & -1.17143 & 2.73508 & 0.73098 & -1.603 & 13 & 0.133 \\
\hline Intermolar width & 0.89286 & 3.66469 & 0.97943 & 0.912 & 13 & 0.379 \\
\hline
\end{tabular}

Abbreviations: Df, degrees of freedom; SD, standard deviation; SE, standard error.

Table 4 Difference in pre- and posttreatment parameters between class I and class II

\begin{tabular}{|l|l|l|l|l|l|l|}
\hline \multirow{2}{*}{$\begin{array}{l}\text { Intercanine width } \\
\text { pretreatment) }\end{array}$} & Equal variance assumed & 2.01364 & 1.41616 & -0.91591 & 4.94319 & 0.175 \\
\cline { 2 - 7 } & Equal variance not assumed & 2.01364 & 1.31954 & -0.73467 & 4.76194 \\
\hline \multirow{2}{*}{$\begin{array}{l}\text { Intermolar width } \\
\text { pretreatment) }\end{array}$} & Equal variance assumed & 2.00649 & 1.36959 & -0.82672 & 4.83970 & 0.062 \\
\cline { 2 - 7 } & Equal variance not assumed & 2.00649 & 1.25231 & -0.62430 & 4.63729 \\
\hline \multirow{2}{*}{$\begin{array}{l}\text { Intercanine width } \\
\text { (posttreatment) }\end{array}$} & Equal variance assumed & 0.59416 & .83162 & -1.12619 & 2.31450 & 0.401 \\
\cline { 2 - 7 } & Equal variance not assumed & 0.59416 & 0.84040 & -1.15520 & 2.34351 \\
\hline \multirow{2}{*}{$\begin{array}{l}\text { Intermolar width } \\
\text { (posttreatment) }\end{array}$} & Equal variance assumed & 2.29545 & 0.80408 & 0.63209 & 3.95882 & 0.646 \\
\cline { 2 - 7 } & Equal variance not assumed & 2.29545 & 0.76606 & 0.70874 & 3.88217 \\
\hline
\end{tabular}

Note: Mean Std. error 95\% confidence interval Class I and Difference of the difference Class II. Lower Upper Difference.

which group is significantly related to which group, as shown in - Table $\mathbf{5}$. It revealed that when comparing intercanine and intermolar distance, there was no statistical significance $(p=\mathrm{b})$ within class I and class II division 1 classes.

\section{Discussion}

The effect of orthodontic extraction on the dental arches has been a matter of controversy in orthodontic communities for a long time. It is well known that arch proportional modifications arise during orthodontic care during the removal of teeth and these changes continue even after the treatment. When the databases were extensively checked for the best prospective research trials investigating the impact of extraction of maxillary first premolars on class I and class II dental malocclusions, data showed that there are several trials investigating the effect of extraction on the arch measurements. Although prospective studies were very small, they were mainly retrospective studies. This research was therefore intended to be a prospective study exploring 
Table 5 Mann-Whitney and Wilcoxon tests between class I and class II

\begin{tabular}{|l|l|l|l|l|l|l|l|}
\hline & Group & $\begin{array}{l}\text { Mean } \\
\text { rank }\end{array}$ & $\begin{array}{l}\text { Sum of } \\
\text { rank }\end{array}$ & $\begin{array}{l}\text { Mann- } \\
\text { Whitney (U) }\end{array}$ & $\begin{array}{l}\text { Wilcoxon } \\
(W)\end{array}$ & $Z$ & $p$-Value \\
\hline $\begin{array}{l}\text { Intercanine width } \\
\text { (pre- and posttreatment) }\end{array}$ & $\begin{array}{l}\text { Group A } \\
\text { (class I) }\end{array}$ & 15.32 & 214.50 & 44.500 & 110.500 & -1.789 & 0.074 \\
\hline & $\begin{array}{l}\text { Group B } \\
\text { (class II) }\end{array}$ & 10.05 & 110.50 & & & \\
\hline $\begin{array}{l}\text { Intermolar width } \\
\text { (pre- and posttreatment) }\end{array}$ & $\begin{array}{l}\text { Group A } \\
\text { (class I) }\end{array}$ & 13.43 & 188.00 & 71.000 & 137.000 & -332 \\
\cline { 2 - 8 } & $\begin{array}{l}\text { Group B } \\
\text { (class II) }\end{array}$ & 12.45 & 137.00 & & & 0.740 \\
\hline
\end{tabular}

improvements in the dimensions of the maxillary dental arch concomitant with maxillary first premolar extraction in the treatment of Angle's class I and class II dental malocclusion in orthodontics.

This study was conducted on 25 pre- and posttreatment study models of randomly selected orthodontic patients. Patients were between the age group of 14 to 20 years. This age range was chosen so that the age difference between patients was minimized as much as possible to ensure more or less the same biological reaction in all patients. Additionally, to ignore the impact of aging on the periodontium, teenagers and young adults were included.

In this study, the intercanine width post treatment tends to increase in both class I and Class II division 1 individuals after first premolar extraction, and the intermolar width tends to decrease in both class I and class II division 1 individuals following first premolar extraction. In the overall sample, it was found that the intercanine width posttreatment increased, whereas the intermolar width posttreatment decreased. The explanation for the reduction in intermolar width after treatment can be the loss of researchers' control over the anchorage parameter or auxiliary instruments.

For class I patients, there was no difference in intercanine and intermolar width, whereas all conditions for class II patients were substantially different. When class I and class II patients were compared for the parameters (intercanine/ intermolar widths), there was no difference statistically.

The interarch shifts of four premolar extraction cases were measured in Boley et al's analysis of $2003 .{ }^{6}$ The upper intercanine span increased $1 \mathrm{~mm}$ according to their observations, whereas the lower arch span increased $1.7 \mathrm{~mm}$ during procedure. The intermolar upper and lower span reduced by 1.7 and $2.1 \mathrm{~mm}$, respectively.

In class II cases, Luppanapornlarp and Johnston ${ }^{7}$ also measured the posttreatment effects of extraction and nonextraction therapy and found that the lower intercanine size increased when the respective teeth was removed when compared with nonremoval procedure.

Gianelly ${ }^{5}$ analyzed the variations in the interarch relationships when teeth were extracted and nonextraction procedure were carried. There were variations in the upper and lower arch span, and the treatment for extraction did not lead to smaller arch span than the treatment for nonextraction. That being said, the population used was not homogeneous, that the included malocclusions in both the categories were not similar. Thus the findings recorded in the analysis by Gianelly could be affected by a huge variety in human variations.

Bishara et $\mathrm{al}^{8}$ evaluated the durability of orthodontic extraction and nonextraction therapy and found that the upper intercanine span of males in the extraction category improved dramatically due to the crowded anterior segment orientation during the process. They did not mention the study group's initial divergences in the arch length of the initial tooth size. In the nonextraction category, the upper and lower intermolar span increased, and in the extraction categories, it decreased.

Based on the definitions described in the literature after extraction, one would have predicted to see narrower arches. Unlike all of these findings, Kim and Gianelly ${ }^{9}$ mentioned that the arch span of the extraction patients became 1 to $2 \mathrm{~mm}$ greater relative to the arch span of the nonextraction categories.

\section{Conclusion}

It can be concluded from present study results that intercanine width posttreatment increased after extraction of first premolars in both class I and class II division 1 cases, intermolar width posttreatment decreased after extraction of first premolars in both, and both when compared were not in accordance.

\section{Conflict of Interest}

None declared.

\section{References}

1 Germec-Cakan D, Taner TU, Akan S. Arch-width and perimeter changes in patients with borderline Class I malocclusion treated with extractions or without extractions with air-rotor stripping. Am J Orthod Dentofacial Orthop 2010;137(6):734. e1-734.e7

2 McNamara L, McNamara JA Jr, Ackerman MB, Baccetti T. Hardand soft-tissue contributions to the esthetics of the posed smile in growing patients seeking orthodontic treatment. Am J Orthod Dentofacial Orthop 2008;133(4):491-499

3 Dierkes JM. The beauty of the face: an orthodontic perspective. J Am Dent Assoc 1987;(Spec No) :89E-95E

4 Zachrisson BU, et al. Maxillary expansion, long-term stability and smile esthetics. World J Orthod 2001;2:266-272 
5 Gianelly AA. Arch width after extraction and nonextraction treatment. Am J Orthod Dentofacial Orthop 2003;123(1): 25-28

6 Boley JC, Mark JA, Sachdeva RC, Buschang PH. Long-term stability of class I premolar extraction treatment. Am J Orthod Dentofacial Orthop 2003;124(3):277-287

7 Luppanapornlarp S, Johnston LE Jr, et al. The effects of premolar-extraction treatment: a long-term comparison of outcomes in "clear-cut" extraction and nonextraction patients. Am J Orthod Dentofacial Orthop 1993;63:257-272

8 Bishara SE, Cummins DM, Zaher AR. Treatment and posttreatment changes in patients with class II, division 1 malocclusion after extraction and nonextraction treatment. Am J Orthod Dentofacial Orthop 1997;111(1):18-27

9 Kim E, Gianelly AA. Extraction vs nonextraction: arch widths and smile esthetics. Angle Orthod 2003;73(4):354-358 